\title{
Study of Pap Smear Examination in Patients with Complaint of Vaginal Discharge
}

\author{
Dr. Kinara Patel ${ }^{1}$, Dr. Himani Patel ${ }^{2}$
}

\begin{abstract}
Introduction: Pap smear examination is the simple way to screen for cervical malignancy now a days. Cervical malignancy is the second most common cancer in female in developing countries. The study was carried out at GMERS medical cllege, sola, ahmedabad in female patients who had mostly complaint of white vaginal discharge. The study highlights and ascertains the utility of cytology in picking up early cervical cancer and associated causative pathogens in patients with vaginal discharge or so called leucorrhoea. Material and Methods: 100 patients were taken for study. Cytopathological changes observed in the cervical squames were graded according to the Bethesda system for reporting cervical cytology. Results: The cytological patterns were found to be 1)Normal10(10\%) 2)Inflammatory-78(78\%) 3)LSIL-3(3\%) 4)HSIL-2(2\%) 5)ASCUS-4(4\%), atrophic vaginitis- 3(3\%). Discussion: Cytological evaluation revealed as expected, maximum number of inflammatory smears(78\%) and cervical squamous intraepithelial lesion was found in 5 cases. Conclusion: Out of 100 cases screened, positive smears were obtained in all cases. Special consideration comprising of 3\% for LSIL, $2 \%$ for HSIL, 4\% of atypical squamous epithelial cells. As it is known that the cervical squamous intraepithelial lesions(SIL) have long course to turn into the invasive stage, its detection early by "Pap Smear" reduces the mortality and morbidity with cervical cancer.Also in cases of leucorrhoea, pap smear helps in identifying, the specific pathogen.
\end{abstract}

Keywords: Leucorrhoea, pap smear - cervical cytology, squamous intraepithelial lesions(SIL),Bethesda system.

\section{Introduction}

Poor genital hygiene in Indian women has been responsible for high prevalence of excessive vaginal discharge.[1] Leucorrhoea is the clinical evidence of infection and can be treated satisfactorily whenever diagnosed. Occurrence of cervical cancer associated with discharge can be easily prevented if detected early. Majority of cancer patients attending hospital present with varying degree of vaginal discharge and cytological monitoring of these subjects is mandatory to know any cellular aberrations in the cervical epithelium as well as the presence of any sexually transmitted diseases(STD's) in the genital tract. Cytological evaluation of cervical smears has been carried out in 100 women attending Gynaecology O.P. D at our hospital with complaint of vaginal discharge. This was performed to investigate the incidence of cervical cytopathology and associated infections of sexually transmitted diseases in patients with vaginal discharge. With this aim the present study was undertaken in 100 women, who presented with history of vaginal discharge. The cytological findings obtained in this cohort have been presented in this paper. The study highlights and ascertains the utility of cytology in picking up early cervical cancer and associated causative pathogens in patients with leucorrhoea. The cervix is both a sentinel for potentially serious upper genital tract infections, a target for viral or chemical carcinogens. Which may lead to invasive carcinoma. The former constitutes one of the most common complaints in gynaecological practice. With the advent of antibacterial therapy for infectious diseases and antiviral agents for viral infections, the emphasis has now moved to chronic diseases. As life expectancy is increasing, malignant diseases are becoming important causes of death. Cervical cancer is the 12th most common cancer among females in the U.K.(2011), accounting for around $2 \%$ of all new cases of cancer in females.[2] cervical cancer used to be the leading cause of cancer death for women in the united states. However in the past 40 years, the number of cases and the number of deaths from cervical cancer have decreased significantly. This decline largely is the result of many women getting regular Pap tests, which can find cervical precancer before it turns into cancer. 12,109 women in the united states were diagnosed and 4.092 women died with cervical cancer.[3] Cervical cancer in India ,is the second most common cancer among women and is the primary cause of cancer related deaths in developing countries.[4] Every year 5,28,000 new cervical cancer cases are being reported. Cervical cancer is the fourth most common cancer affecting women worldwide, after breast, colorectal and lung cancers [5]. Thus cytological screening should gain much popularity and should be accessible to all. It is recommended as part of routine medical examination in gynaecological practice in the context of health maintenance programme. The present study includes the various lesions of cervix in women complaining of leucorrhoea with the help of cervical cytology with Papanicolaou stain and cervical punch biopsy, with main emphasis on the precancerous and invasive cancers of cervix and to study the various risk factors in relation to the premalignant and malignant conditions of cervix.[1]

\section{Material and Methods}

The present study included 100 women who came with the complaint of vaginal discharge. As told by the patients on questioning, the discharge was found to be of different types -white discharge, yellowish discharge, greenish discharge, blood stained and foul smelling discharge. A total of 100 cases were included in the study with women of age ranging from 15-45 years, complaining of vaginal discharge. Smears were taken with a thorough history in particular reference to age at first child birth, parity, personal and genital hygiene, history of husband suffering from any sexually transmitted diseases, vaginal discharge, mass per vaginum, duration of labour and history of sexually transmitted diseases were elicited. Cervix was visualized with Sim's speculum and associated conditions like erosion, ectropion, hypertrophy, endocervicitis,suspicious growth on cervix and elongation of cervix were noted. After a thorough vaginal examination Pap smears were taken. Smears were immediately fixed in 


\section{International Journal of Science and Research (IJSR) \\ ISSN (Online): 2319-7064 \\ Index Copernicus Value (2013): 6.14 | Impact Factor (2014): 5.611}

absolute alcohol and stained according to the papaniculaous technique. The cytopathological changes observed in the cervical squames were graded according to the Bethesda system for reporting cervical cytology.[6]Simultaneous Wet film examination was performed . For Wet film preparation, a cervical smear is taken with the help of Ayre's spatula and spread on a clean glass slide. A drop of normal saline is put on the slide. Place a cover slip on the drop. Then the smear is examined immediately first under low power later under high power. Various microorganisms like Trichomonas vaginalis(motile and flagellated), Candida(branched hyphae) and viruses (Herpes) were identified in wet film preparations, as detailed in the results.

\section{Observations \& Results}

The cytological patterns observed were: Normal $=10(10 \%), \quad$ Inflammatory $=78(78 \%), \quad$ LSIL $=3(3 \%)$, HSIL $=2(2 \%), \quad$ ASCUS $=4(4 \%)$, atrophic vaginitis $=3(3 \%)$. High percentage of smears were inflammatory(78), cervical squamous intra epithelial lesions were seen in 5 cases $(5 \%) .3$ cases were categorized as LSIL and 2 cases as HSIL. Presence of sexually transmitted diseases(STD's) were also investigated in the smears of the study group.

The distribution of different types of pathogens detected were: Trichomonas infection $=25(25 \%)$, Candida albicans $=7(7 \%)$, Condyloma $(\mathrm{HPV})=1(1 \%)$

\section{Discussion}

In the present study "Pap" smears of 100 women complaining leucorrhoea are collected from gynaecology O.P.D at our hospital. The cases belonged to different age groups in reproductive life, socio-economic classes and with a complaint of vaginal discharge with clinical findings. The cytological evaluation carried out on100 women with vaginal discharge revealed as expected maximum number of inflammatory smears(78\%).SIL's were found in 5 cases(5\%) and thus ascertains the utility of cytological surveillance in symptomatic women for early detection of cervical cancer. This result is comparable to the work done by Pairwuti S.[18] pelvic examinations done in 1906 women with the range of ages were between $14-85$ years. $74.7 \%$ of cases had undergone Pap smear examinations. The percentage of clinical diagnosis in women, who underwent pelvic and Pap smear examinations 36.6(29). No abnormal findings 14.9(10.5), vulvovaginitis and leucorrhoea. 10.1(9.7)cervicitis and cervical erosion. 5.6(1.9) bleeding per os, 3.6(.3) abortion and 3.3(1.3) adnexitis. The mean age of women with various diseases were 27 years in cases of abortion, 30-34 years in women with the inflammation of vulva, vagina, cervix and adnexae including bleeding per os. 41-45 years in women with cervical polyps, suspected carcinoma, precancer and carcinoma of cervix combined with myoma uteri,48 years women with prolapsed. Cytology thus facilitates in picking up precancerous cervical lesions. In women complaining of leucorrhoea, it is essential to know whether the discharge is specific (caused by a pathogen) so that the treatment can be contemplated accordingly. During present investigation maximum number were associated with Trichomonas infection (25\%) followed by candida $(5 \%)$ detected in 7 cases, 1 of them (1\%) showed changes of cases trichomonas infection, $5.3 \%$ Candida albicans cases and SIL's were recorded in condyloma infestations in the present study. This result is comparable to the work done by Sanchez SE, Koutsky, Fernandez to managing abnormal vaginal discharge, chlam 1.6\%, trichomoniasis in $7.3 \%$, Bacterial vaginosis in 30\%. A chief complaint yellow vaginal discharge had Trichomoniasis(of $50 \%$ ) or Bacterial vaginosis. [9 ] This result is comparable to the work done by viswanath and talwar, Syndromic management of vaginal discharge. Most common infection was Bacterial vaginosis(26\%), Chlamydia trachomatis infection was $12.2 \%$, Trichomoniasis $10 \%$, syphilis $2.2 \%$. Atleast 1 sexually transmitted infection was detected in $21.9 \%$ of women. N. Gonorrhoea was not isolated.[ 10] In the work done by the Deodhar L and Karnad, G. Vaginalis was isolated from $52.4 \%$ of patients with non-specific vaginitis.[11] In the work done by Rewari N, Chandha P and Kriplani in symptomatic cu T 200 users suffering with nonspecific vaginitis found Gardnerella vaginalis 79\%.[12]The result is comparable to the work done by the Yogita M. Patel. Inflammatory lesions $=47 \%$ and $\mathrm{SIL}=10.5 \%$.[13] and with Noor Afshan study, Inflammatory lesions $=57 \%$, SIL $=20 \%$. [14] and also with Karuma study Inflammatory lesions $=48 \%$, SIL $=12 \%$.[23] (Table-1\&2)

Table 1

\begin{tabular}{|c|c|c|c|c|c|c|c|}
\hline Name of the study & $\begin{array}{c}\text { Present } \\
\text { study }\end{array}$ & $\begin{array}{c}\text { Yogita M. } \\
\text { Patel13(2012) }\end{array}$ & $\begin{array}{c}\text { Chauhn et al } \\
(1990)\end{array}$ & $\begin{array}{c}\text { Noor. Afshan et } \\
\text { al15 (1995) }\end{array}$ & $\begin{array}{c}\text { Misra et } \\
\text { al1(1997) }\end{array}$ & $\begin{array}{c}\text { Sepehrn Tabrize } \\
\text { et al (1999) }\end{array}$ & $\begin{array}{c}\text { Karuma et al } \\
23(2003)\end{array}$ \\
\hline No. of cases & 100 & 200 & 5778 & 400 & 1634 & 460 & 100 \\
\hline Inflammatoy lesion $(\%)$ & 78 & 47 & 69.19 & 57 & 57.4 & 23.30 & 48 \\
\hline SIL(\%) & 5 & 10.5 & 2.28 & 20 & 4.8 & 12.58 & 12 \\
\hline
\end{tabular}

Table 2

\begin{tabular}{|c|c|c|c|}
\hline $\begin{array}{c}\text { Name of the } \\
\text { study }\end{array}$ & $\begin{array}{c}\text { Present } \\
\text { study }\end{array}$ & $\begin{array}{c}\text { Yogita M. } \\
\text { Patel 13(2012) }\end{array}$ & $\begin{array}{c}\text { Karuma et al } \\
23(2003)\end{array}$ \\
\hline No. of cases & 100 & 200 & 100 \\
\hline ASCUS(\%) & 4 & 6.5 & 6 \\
\hline LSIL(\%) & 3 & 3.5 & 7 \\
\hline HSIL(\%) & 2 & 7 & 5 \\
\hline
\end{tabular}

In the work done by Ghazal - Aswad et al , ASCUS $=2.9 \%$, LSIL $=1.1 \%$ and HSIL $=0.9 \%$. [16] In the work done by Ranabhat sk et al ASCUS $=0.23 \%, \quad$ LSIL $=0.23 \%$ and
HSIL $=0.68 \%$.[17] The study thus reveals a possible relationship between bacterial and fungal STD's and causation of precancerous changes in the cervical epithelium. Detection of both STD's and SIL at the same time in cytology smear helps in timely treatment which relieves the patient from the aggravation of symptoms as well as minimizes the risk of progression of SIL to cervical malignancy. The study revealed a rising incidence of SIL with increasing age and parity. Hence cytological investigation should be performed on all women complaining of discharge to detect the presence of STD's 


\section{International Journal of Science and Research (IJSR) \\ ISSN (Online): 2319-7064 \\ Index Copernicus Value (2013): 6.14 | Impact Factor (2014): 5.611}

and premalignant lesions of the cervix. Cancer cervix is being the leading cause of morbidity and mortality in women, efforts are going on for the last century, so that immediate intervention can be done at an early stage, to detect cancer of cervix. As the reproductive age group taken in the study, many cases showed infection mostly due to Trichomoniasis, more commonly related to the hygiene of the individual. Cytology revealed that LSIL and HSIL are more common in the age group of 40 years and above. So, the incidence of SIL showed rise with increasing age and parity, women who had initiated sexual life and given birth to one or more children before the age of 18 years. Pap smear examinations in women post treated for genital organ diseases by operation and radiation were examined by Pairwuti S. for consideration of treatment of choice.[18] one case of nuclear Atypia was reported, showed higher risk of developing SIL than those with reparative Atypia.[19] women with para- 1 and $<20$ years age, no cervical SIL was recorded. Cytology revealed the step wise increase in the incidence of positive smears wit increased span of marital life. Thus, in the present study we have recorded 3 cases of LSIL in women with marital life of $20-25$ years, whereas 2 cases HSIL in women with marital life of 25 - 35 years and 4 cases of ASCUS in women with marital life of 15 years. Low socio-economic status, illiteracy, multi parous and poor personal hygiene were also found to be exceedingly high with increasing incidence of positive smears. Also ill nourishment and vitamin deficiencies are also found to be high among those with HSIL. Maximum number of SILS are reported from patients with cervical erosion, endocervicitis and hypertrophied cervix.

Stringent follow up is important in the cases, where the discrepancy exists between cervical cytology and the initial biopsy, because a significant number of these patients will have SIL revealed in subsequent studied.[24]

\section{Conclusions}

Out of 100 cases screened, satisfactory smears were obtained in all cases , 78\% of inflammatory smears , 3\% for LSIL, 2\% for HSIL, 4\% ASCUS. In women with postradiation carcinoma of cervix complaining of vaginal discharge, smear showed pleomorphism in endo-cervical and squamous epithelial cells. Biopsy was done in a case of nuclear atypia, found to be chronic non-specific ectocervicitis. Biopsy was done in a case of granulomatous inflammation found to be papillary erosion of cervix. Biopsy was done in another 3 cases with Trichomonas infestation, 2 cases found to be chronic non-specific ecto cervicitis and 1 case with plenty of mucus and mono nuclear inflammatory cell collections. The various risk factors like early age at marriage, increased marital life, increased parity and poor socio-economic status are known to be directly related to the increased incidence of all cervical SILs. Also early age at $1 \mathrm{st}$ child birth, illiteracy, poor personal and genital hygiene, poor nutritional status, vitamin deficiencies and history of chronic leucorrhoea are associated with high incidence of cervical SIL. As it is known that the cervical squamous intraepithelial lesions(SIL) have long course to turn into the invasive stage. So, its detection early by "Pap Smear" reduced the mortality and morbidity with cervical cancer. This cytological screening should gain much popularity and should be accessible to all. It is recommended as part of routine medical examination in gynaecological practice.

\section{References}

[1] Misra J.S.Das zk and Harish A cytological studies in women complaining of leucorrhoea. Journal of cytology. 14(1):11,1997.

[2] http://www.ons.gov.uk/ons/index.html.

[3] National institutes of health. Cervical Cancer .NIH Consensus satetment.1996;14(1):1-38. U.S Cancer statistics working group. United States Cancer Statistics: 1999-2011. Incidence and Mortality Web; based report.

[4] http://www.medindia.net/patients/patientinfo/cervicalca ncer-incidence.

[5] Bray F, Ren JS, Masuyer,Ferlay J(2013). Global estimates of cancer prevalence for 27 sites in the adult population in 2008. Int I Cancer,132(5): 1133-1145. http://dx.doi.org/10.1002/ijc.27711

[6] The 1998 Bethesda system for reporting cervical/vaginal cytologic diagnosis. Developed and approved at the national cancer institute workshop in Bethesda, Maryland, Dec. 12-13,1988: HUMAN PATHOLOGY, Vol. 21, No. 7,(July 1990); 704-708.

[7] Harvey M. Cramer, and Suzanne: Cytomorphologic correlates of Human Papiloma Virus infection in the Normal cervico vaginal smear: Acta Cytologica Vol.41,No.2/Mar 1997;261-268.

[8] Pair wuti S. department of Obstetrics \& Gynaecology, Faculty of Medicine, Siriraj Hospital, Mahidol University, Bangkok, Thailand: Pap smear examinationof women at the out-patient department of Siriraj Hospital: J Med Assoc Thai 1990 Sep;73(9);4738.

[9] Sanchaz SE, Koutsky and Fernandez A. Department of Epidemiology, University of Washington, Seattle 98109,U.S.A.:Rapid and inexpensive approaches to managing abnormal vaginal discharge or lower abdominal pain, an evaluation in women attending gynaecology and family planning clinics in peru: Sex Transm infect 1998 June, 74 suppl 1:585-94.

[10] Viswanath S, Talwar V, Prasad R, Coyajik, Elias CJ, de Zoysa I, Department of Microbiology, University College of medical Sciences, New Delhi, India: Syndromic management of vaginal discharge among women in a reproductive health clinic in India: Sex Transm infect 2000 Aug, 76(4):303-6.

[11]Deodhar L, Karnad J. Department of Microbiology, lokmanya Tilak Municipal Medical college, Bombay: Invitro adhesiveness of Gardnerella Vaginalis Strains in relation to the occurance of clue cells in Vaginal discharge: Indian J.Med Res 1994 August,100;59-61.

[12]Rewari N, Chadha P and Kriplani A Department of Obstetrics and Gynaecology, MAMC Hospital New Delhi: Microbiological Study of vaginal discharge associated with the use of cu T 200: J.Indian Med Assoc 1991 Oct, 1989(10);289-91.

[13] Yogita.M.Patil, R.N.Consai. Pap smear study of cervical cytology. Int J Sceintific Research.425,426, Vol:3,issue 11, Nov 2014. ISSN no 2277-8179.

[14] Chu et al Ref 42 of IJSR. Yogita.M.Patil, R.N.Consai. Pap smear study of cervical cytology. Int J Sceintific 
Research.425,426, Vol:3,issue 11, Nov 2014. ISSN no 2277-8179.

[15] Noor Afshan, Sabposh R. Sherwani, K.Tewari, Tamkin khan and A.Gupta: Cytomorphological and histopathological assessment of premalignant and malignant lesions of cervix. Journal of Obs \& gynecol of India.45(4):553,1995.

[16] Ghazal-Aswad S, Gargash H, Badrinath $\mathrm{P}$ et al: Cervical smear abnormalities in the United Arab Emirates. A pilot study in the ---Cytologica.2006;50:41-97.

[17] Ranabhat Sk,Shrestha R,Tiwari M.Analysis of abnormal epithelial lesions in cervical Pap smears in Mid-Wester Nepal.Journal Nepal.2011;1:30-33.

[18] Pair wuti S. department of Obstetrics \& Gynaecology, Faculty of Medicine, Siriraj Hospital, Mahidol University, Bangkok, Thailand: Pap smear examination of women post-treated for genital organ diseases by operation and radiation: J.Med Assoc thai 1990 Nov ;73(11);610-4.

[19] Francisco Alameda Quitllet, Maria conangla Morta, Angeles canas, Elena Castellanos and Ramon Carreras : Cytologic Atypia. Clinical significance and follow-up Recommendations: Acta cytol 1997 ; 41 :504-506.

[20] Mary Beth. Anderson and Breece A Jones : False positive cervicovaginal cytology, A follow-up study: Acta cytol 1997:41:1697-1700.

[21]Dhiraj BNikumbh, RD Nikumbh,VD Dombale, SV Jagtap, SR Desai.: Cervicovaginal Cytology:Clinicopathological and Social Aspect of Cervical Cancer Screening in Rural Maharastra, India.International journal of health sciences and research.1/2012

[22] K.Park:Park's text book of preventive and social medicine, 18th Ed.M/S.Banarsidas bhanton publishers, 1167, Premnagar 307 308,2005.

[23] Karuna, gaspanal v, Van Dan Brule R: The clinical profile and cervical cytomorphology, Indian journal of pathol.microbiol.46(2) 782003.

[24] Abdullah LS.Pattern of abnormal pap smears in developing countries: A report from a large referral hospital in Saudi Arabia . 2001 Bethesda system. Ann Saudi Med 2007;27:268-72 